\title{
Lifestyle recommendations reduced blood pressure in patients with above optimal blood pressure
}

\author{
Appel LJ, Champagne CM, Harsha DW, et al. Effects of comprehensive lifestyle modification on blood pressure control: main \\ results of the PREMIER clinical trial.JAMA 2003;289:2083-93.
}

\section{QUESTION: In patients with above optimal blood pressure (BP), what is the relative effectiveness of 2 behavioural interventions (established lifestyle recommendations [ELR] and ELR plus the Dietary Approaches to Stop Hypertension [DASH] diet) compared with advice only?}

\section{Design}

Randomised (allocation concealed*), blinded (data collectors),* controlled trial with 6 months of follow up (PREMIER Clinical Trial).

\section{Setting}

4 clinical centres in Baltimore, Maryland; Baton Rouge, Louisiana; Durham, North Carolina; and Portland, Oregon, USA.

\section{Patients} (mean age 50 y, 62\% women), had above optimal BP (mean systolic BP 120-159 mm Hg and diastolic BP $80-95 \mathrm{~mm} \mathrm{Hg}$ during 3 screening visits), were not taking antihypertensive medication, and had a body mass index of 18.5-45.0. Exclusion criteria were regular use of drugs affecting BP; target organ damage or diabetes; use of weight loss medication; previous cardiovascular event; congestive heart failure; angina; cancer diagnosis or treatment in the previous 2 years; consumption of $>21$ alcoholic drinks/week; and pregnancy, planned pregnancy, or lactation. $87 \%$ of patients completed all 3 follow up visits at 6 months.

\section{Intervention}

268 patients were allocated to the ELR group (weight loss for overweight participants, reduced sodium intake, increased physical activity, and limited alcohol intake). 269 patients were allocated to the ELR plus DASH diet group (reduced fat and cholesterol; increased potassium, calcium, magnesium, protein, and fibre). Patients in both of these groups had 14 group meetings and 4 individual counselling sessions during the initial 6 months. 273 patients were allocated to the advice group (a single 30 min individual session, delivered by a dietitian).

For correspondence: Dr LJ Appel, Johns Hopkins Medical Institutions, Baltimore, MD, USA.

lappel@jhmi.edu

A modified version of this abstract appears in Evidence-Based

Nursing.

Analysis was by intention to treat. Patients in the ELR and ELR plus DASH groups had greater reductions in
810 generally healthy adults who were $\geq 25$ years of age

systolic and diastolic BP than patients in the advice group (table); the 2 behavioural intervention groups did not differ (table).

\section{Conclusion}

Patients with above optimal blood pressure (BP) who received established lifestyle recommendations, with or without the Dietary Approaches to Stop Hypertension diet, had greater reductions in BP than those who received advice only.

*See glossary.

\section{COMMENTARY}

The PREMIER study shows that lifestyle interventions can have clinically important effects on BP and progression to overt hypertension. Previous work focused on weight loss and dietary sodium reduction. ${ }^{1}$ The DASH diet expanded these concepts to increase potassium consumption with fruits and vegetables and increase calcium intake with low fat dairy products. ${ }^{2}$ A key issue has been whether addition of the DASH diet to standard recommendations would result in improved BP. The behavioural lifestyle intervention was intensive, and this translated into weight reduction (on average $5 \mathrm{~kg}$ ) and reduction in urinary sodium excretion. The resultant drops in BP were relatively small in absolute magnitude, but intervention patients were more likely to have optimal BP at 6 months. The non-significant differences between the ELR and the ELR plus DASH groups suggest that clinicians should focus on promoting weight loss through exercise and caloric restriction including dietary sodium reduction.

We now have strong evidence in hypertension and in diabetes prevention ${ }^{3}$ that lifestyle interventions are possible and can lead to clear cut benefits for patients. The challenge will be to effectively implement these findings in clinical practice with a full spectrum of patients. Clinicians can recommend these lifestyle changes but should be realistic and expect that only a select group of self motivated patients may adopt them. Public health officials should take heed of the results of this trial and devise creative and cost effective ways to implement them broadly.

Allan V Prochazka, MD Denver Veteran's Administration Medical Center Denver, Colorado, USA

Established lifestyle recommendations (ELR) or ELR plus Dietary Approaches to Stop Hypertension (DASH) diet $v$ advice only for above optimal blood pressure $(B P) \dagger$

\begin{tabular}{llll}
\hline \multicolumn{2}{l}{ Mean between group differences in BP change $(95 \% \mathrm{Cl})$} \\
\hline ELR $v$ advice & $\begin{array}{l}\text { ELR } \\
\text { advice }\end{array}$ & DASH $v$ & $\begin{array}{l}\text { ELR + DASH } v \text { ELR } \\
\text { Outcomes }\end{array}$ \\
Systolic BP $(\mathrm{mm} \mathrm{Hg})$ & $-3.7(-5.3$ to -2.1$)$ & $-4.3(-5.9$ to -2.8$)$ & $-0.6(-2.2$ to 0.9$) \ddagger$ \\
\hline Diastolic BP $(\mathrm{mm} \mathrm{Hg})$ & $-1.7(-2.8$ to -0.6$)$ & $-2.6(-3.7$ to -1.5$)$ & $-0.9(-2.0$ to 0.2$) \ddagger$ \\
\hline
\end{tabular}
$\dagger \mathrm{Cl}$ defined in glossary.

‡Not significant. 